\title{
O uso consciente da tecnologia como elemento essencial para uma inclusão sociodigital efetiva
}

\author{
Silvana Maria Carbonera ${ }^{1}$, Andreia de Jesus ${ }^{1}$, \\ Alexander Robert Kutzke ${ }^{1}$ e Izabel do Rocio Costa Ferreira ${ }^{1}$
}

${ }^{1}$ Setor de Educação Profissional e Tecnológica

Universidade Federal do Paraná

Curitiba - PR

\{silvana.carbonera, andreia.jesus, alexander, izabel.ferreira\}@ufpr.br

\begin{abstract}
The present work aims to provoke reflections about the conscious use of technologies as an essential element for an effective socio-digital inclusion. To this end, the authors present reflections by analyzing their extension practices in socio-digital inclusion projects with a scientific basis. From these first reflections, it was possible to outline a concept of what is the conscious use of technologies. In addition, among possible future perspectives for research on the topic, the following question emerged as a starting point: how to systematize learning processes that promote the conscious use of technologies?
\end{abstract}

Resumo. O presente trabalho tem como objetivo provocar reflexões acerca do uso consciente de tecnologias como um elemento essencial para uma inclusão sociodigital efetiva. Para tanto, os autores iniciaram as reflexões analisando suas práticas extensionistas em projetos de inclusão sociodigital e fundamentando-as com base científica. Com o fechamento dessas primeiras reflexões, foi possível delinear um conceito prévio do que é o uso consciente de tecnologias. Além disso, dentre possíveis perspectivas futuras de pesquisa sobre o tema, vislumbrou-se como um dos pontos de partida o seguinte questionamento: como sistematizar processos de aprendizagem que promovam o uso consciente de tecnologias?

Palavras-chave: inclusão sociodigital, efetividade, uso consciente de tecnologia

\section{Introdução}

Até que ponto uma pessoa que usa tecnologias digitais realmente sabe quais são as consequências de seu uso e das escolhas que faz no mundo digital? O domínio do aspecto técnico garante que o conteúdo acessado seja utilizado de forma consciente? Ter senso crítico no uso das tecnologias digitais é suficiente para garantir uma inclusão sociodigital efetiva? Ou, além da habilidade de analisar técnica e conteúdo, é necessário tomar decisões pautadas em outros critérios para que o uso consciente das tecnologias digitais se torne realidade e represente um elemento que conduza à efetiva inclusão sociodigital?

Tendo como ponto de partida estas e outras questões relacionadas ao uso consciente de tecnologias, os integrantes do Grupo de Pesquisa Educação e Tecnologias: Pessoas e Protagonismos, da Universidade Federal do Paraná (UFPR), desenvolvem atividades de pesquisa e de extensão universitária em áreas específicas, compatíveis 
com a formação multidisciplinar dos pesquisadores que são da área da saúde, da informática/computação e jurídica, mas com um elemento comum, a preocupação com o uso consciente de tecnologias como elemento essencial para a efetiva inclusão sociodigital.

É importante frisar que tal preocupação surgiu a partir de uma realidade comum vivenciada pelos autores, membros do referido Grupo de Pesquisa, em atividades de extensão realizadas junto à Escola Estadual Dom Pedro II, em 2016 e 2017, e ao Colégio Estadual Santa Rosa, em 2018 e 2019, ambos em Curitiba/PR. Como a escolha metodológica de produção de conhecimento do Grupo de Pesquisa Educação e Tecnologias: Pessoas e Protagonismos assenta na articulação entre pesquisa e extensão universitária, a produção de conhecimento daí decorrente se traduz tanto em produção científica, conforme [de Jesus et al. 2020], quanto em novas questões nascidas da observação empírica das atividades extensionistas realizadas nas unidades escolares acima referenciadas.

Neste sentido, a articulação entre pesquisa e extensão produz conhecimento a partir da experiência [Castro 2004], agregando a tal processo a presença de outras pessoas, membros da comunidade na qual as atividades foram desenvolvidas, além do docente e do estudante. Trata-se de um processo no qual o conhecimento produzido "circula, [...] tem possibilidade de ser testado e de ter agregado a ele novos valores", deixando de ser uma repetição para se tornar, nas palavras de [Castro 2004, p. 3], emancipador. E é neste sentido que o conhecimento produzido pode ser qualificado como "mais humano, mais cidadão, mais centrado nas questões cruciais do mundo à sua volta" [Castro 2004, p. 4].

Em tal contexto, o estudo e a discussão da relação entre o uso consciente de tecnologias e a efetividade da inclusão sociodigital é uma temática presente no quotidiano do grupo, tanto no âmbito da pesquisa, coletiva e individual, quanto no da realização de extensão universitária. Tal preocupação deu origem a este primeiro estudo, cujo objetivo inicial é refletir acerca de um percurso formativo que parte da alfabetização digital, passa pelo letramento digital e chega à inclusão sociodigital com o uso consciente de tecnologias digitais em uma Sociedade da Informação, como é a realidade vigente. De certa forma, o que se pretende, com estas reflexões, é apontar questões e aspectos relevantes para a construção de um conceito possível para o que pode ser o uso consciente de tecnologias.

É possível afirmar que a sociedade, após a inserção das tecnologias no contexto de suas atividades, pode ser denominada de 'Sociedade da Informação', termo utilizado nestas reflexões. Segundo [Castells 2002] as cinco características fundamentais dessa sociedade são: (1) a informação é a sua matéria-prima; (2) os efeitos das novas tecnologias têm alta penetrabilidade; (3) há predomínio da lógica de redes; (4) existe flexibilidade; e (5) crescente convergência de tecnologias.

É importante reforçar aqui a característica um (1), em que para [Castells 2002] o desenvolvimento da tecnologia tem como objetivo permitir ao homem acessar, adquirir e atuar sobre a informação, numa posição mais ativa. Logo, as tecnologias, com suas variações e evoluções, afetam diretamente os processos de trabalho e as formas de produção e relacionamento entre as pessoas (característica 2). Isto porque a informação é parte integrante de toda atividade humana, individual ou coletiva [Castells 2002].

Assim sendo, é necessário trazer para o contexto dessa sociedade processos e projetos de formação que tragam em sua essência a 'Inclusão Digital'. Mas, esta Inclusão 
Digital deve ir além da formação técnica, deve ter uma abrangência muito maior, que inclua questões sociais e culturais, que também são afetadas com a inserção das tecnologias, a fim de proporcionar aos indivíduos autonomia e protagonismo na Sociedade da Informação.

Já é possível encontrar na literatura questionamentos sobre a efetividade de projetos de Inclusão Digital, conforme indaga [Jesus 2012]:

"[...] qual seria realmente o objetivo principal de um projeto que visa à inclusão digital de seus participantes? Oportunizar o acesso ao computador e à internet? Desenvolver habilidades relacionadas ao uso dessas tecnologias? Formar a consciência crítica de sua comunidade participante com relação ao uso dessas tecnologias? Ou formar pessoas que tenham consciência de que é possível exercer a cidadania a partir do uso do computador e da internet?" [Jesus 2012, p. 62]

Esses questionamentos deixam claro que para um projeto ou processo de Inclusão Digital ser efetivo a sua abrangência deve ir além da disponibilização de equipamentos, acesso à Internet e formação técnica. Pois, saber utilizar a tecnologia e ter acesso à Internet não significa que o cidadão sabe o que fazer com o dado ou informação adquiridos por meio dessas tecnologias.

Um processo de Inclusão Digital deve promover a capacitação tecnológica, deve dar condições de formação de senso crítico suficiente para analisar os conteúdos acessados e as técnicas utilizadas e deve proporcionar ferramentas de inclusão sociodigital, com o uso consciente do que está disponível no mundo digital. A tecnologia, neste caso, é a ferramenta da Sociedade da Informação que pode ser utilizada para a promoção da inclusão sociodigital.

Logo, quando se planeja um projeto ou processo de Inclusão Digital, este deve ser includente do ponto de vista técnico e ter uma abrangência que garanta que não será excludente do ponto de vista social. A Figura 1 demonstra a ideia da essência de um processo de Inclusão Sociodigital e nas próximas seções serão discutidos os elementos desse processo.

\section{Alfabetização Digital}

$\mathrm{Na}$ literatura é possível encontrar vários trabalhos que já abordaram o conceito de Alfabetização Digital, como por exemplo: [Jesus 2012], [Colello 2016], [de Lima and Zavam 2016]. Estes autores trazem o conceito de alfabetização e contrapõe com o conceito de letramento. É importante ressaltar aqui que estes dois conceitos se complementam, pois não é possível tornar uma pessoa letrada sem antes alfabetizá-la. Isto é válido também no contexto das tecnologias digitais.

Uma definição de Alfabetização Digital é apresentada por [Tarouco and Ávila 2007, p. 1] : “a alfabetização digital está relacionada à aquisição de habilidades básicas para o uso de computadores e da Internet”. Ou seja, conforme [Jesus 2012] em seu estudo, a Alfabetização Digital possibilita ao indivíduo uma visão das possibilidades de recursos e uso desses recursos digitais em suas atividades diárias. Porém, esse é só o primeiro passo para uma Inclusão Sociodigital. Além disso, para promover a Alfabetização Digital é necessário democratizar o acesso às tecnologias e a 


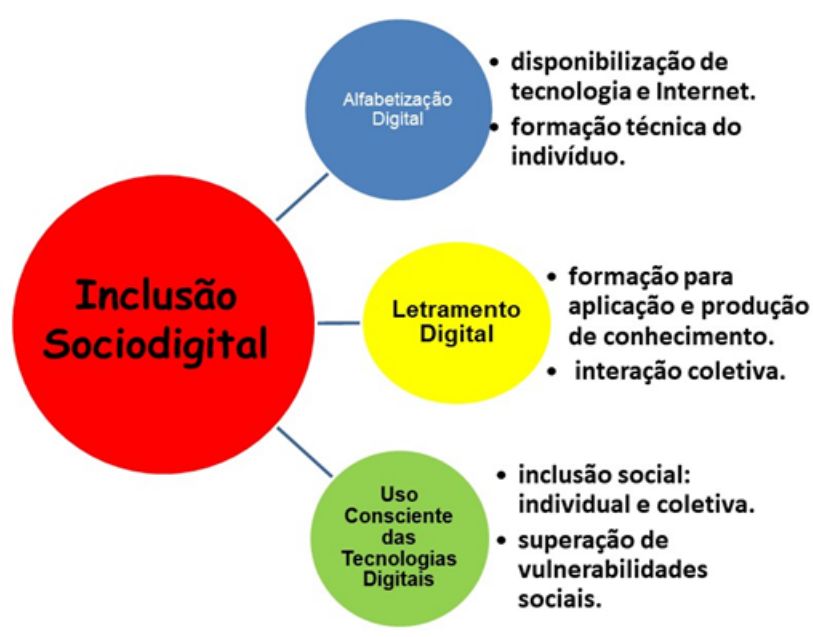

Figura 1. Elementos de um projeto de Inclusão Sociodigital [Os Autores 2020].

Internet. Porém, a disponibilização dos recursos é somente um meio para alcançar um fim maior que é o uso consciente das tecnologias digitais.

E quando se pensa em Sociedade da Informação a Alfabetização Digital é fundamental pois, antes de relacionar dados e informações para a geração de novos conhecimentos e aplicação na solução de problemas, é necessário desenvolver habilidades técnicas de aquisição desses dados por meio dos recursos mais utilizados na sociedade atual, as tecnologias digitais e a Internet.

É claro que as novas gerações (Y, Z, Alpha) já usam em suas atividades diárias, desde a primeira infância, a tecnologias digitais. Porém, isso não garante que elas tenham uma alfabetização digital efetiva, pois apesar de terem habilidades de manuseio desses recursos digitais, muitas vezes não tem conhecimento de como aplicar esses recursos em atividades do dia a dia e até mesmo na construção de novos conhecimentos, como é possível verificar em atividades extensionistas de inclusão digital [Rosa et al. 2019, Ferreira et al. 2019, de Jesus et al. 2020]. Logo, é importante, dentro do processo de Inclusão Sociodigital, trabalhar todos os níveis, desde a alfabetização digital perpassando pelo letramento digital até alcançar o uso consciente das tecnologias digitais.

\section{Letramento Digital}

Preliminarmente, é importante considerar que a expressão "letramento" admite vários conteúdos, sejam eles relacionados ao aprendizado de um idioma ou de uma linguagem digital [Rezende 2016, p. 95]. Também é possível encontrar na doutrina que trata do tema o uso da expressão "literacia", com a ressalva que as duas expressões não são sinônimas [Gabriel 2017, p. 83]. Todavia, nenhum dos dois aspectos será aprofundado neste trabalho pois um de seus objetivos foi apontar aspectos que conduzam à inclusão sociodigital com o uso consciente de tecnologias digitais.

Uma vez ocorrido o processo de alfabetização digital, o letramento digital é o próximo passo para uma completa inclusão sociodigital. Ou seja, conhecidos os aspectos técnicos necessários para dominar os recursos digitais disponíveis, torna-se possível e 
necessário transcender o ato repetitivo, perguntando para que ele serve, qual é o sentido de sua realização e quais são as consequências de sua prática.

Se o sentido de letramento for relacionado ao aprendizado de idiomas, seu conteúdo remete à aquisição das habilidades de leitura e escrita, necessárias à ampla compreensão do que se está lendo e produzindo. Todavia, ao ser acrescentado o adjetivo "digital", a expressão apresenta novo sentido pois, conforme pondera [Rezende 2016, p. 101], não se trata somente de mudar o suporte físico de escrita e leitura mas sim, a partir do uso de uma nova plataforma, a digital, de compreender de que forma os recursos por ela apresentados podem ser utilizados para alcançar o objetivo do usuário.

Em certa medida, é possível inferir que o letramento digital presume a construção de um senso crítico tanto dos conteúdos acessados quanto das ferramentas digitais disponíveis e utilizadas. Desta forma, o processo de letramento passa pelo desenvolvimento da capacidade individual de avaliar atos praticados no ambiente digital e da habilidade de analisar os conteúdos acessados, antes de tirar uma conclusão ou de tomar uma decisão.

É possível constatar que o letramento digital não é um processo linear e tranquilo, exige um agir positivo da pessoa interessada em adquirir tal habilidade na medida em que elas se dispõem a refletir sobre o que estão usando, o que estão fazendo e o que estão acessando.

Uma reflexão interessante sobre o tema foi feita por [Buckingham 2010], para quem o letramento digital é um processo complexo, composto pela habilidade de localizar e selecionar um material desejado, recuperando informações, e também pela capacidade de avaliar e utilizar criticamente a informação obtida. Em suas palavras, "significa fazer pergunta sobre as fontes dessa informação, os interesses de seus produtores e as formas como ela representa o mundo, compreendendo como estes desenvolvimentos tecnológicos estão relacionados a forças sociais, políticas e econômicas mais amplas" [Buckingham 2010, p. 49].

[Buckingham 2010] destaca quatro "aspectos conceituais" do letramento digital. O primeiro deles remete à "representação", característica que tem a mídia digital de apresentar interpretações da realidade, via de regra carregadas de valores de quem as produz. O letramento, neste sentido, deve dar à pessoa condições de avaliar o que está diante de si e identificar as motivações de quem as produziu, definindo se concorda, ou não, com o que vê. Ou, ainda, de "abordar questões sobre autoridade, confiabilidade e tendência" do material ao qual ela tem acesso [Buckingham 2010, p. 50]. Em termos práticos, trata-se, por exemplo, de conseguir analisar qual é o sentido e o objetivo de uma notícia que circula em uma rede social, identificando se ela é real ou se é uma fake news, questionando sua veracidade e não a tomando como verdade irrestrita.

O segundo aspecto é denominado pelo autor de "língua". Neste sentido, é necessário não somente dominar a linguagem da comunicação digital mas, também, compreender de que modo ela funciona. Entende [Buckingham 2010] que o processo de letramento digital deve "envolver uma consciência sistemática de como são construídos os meios digitais e da retórica única da comunicação interativa [...]" [Buckingham 2010, p. 50]. Isso inclui, também, a compreensão de como sites são projetados e estruturados. Uma pessoa com letramento digital deve saber, por exemplo, que ao navegar em um determinado site, dependendo de qual for, ela terá um cookie instalado em sua máquina, que 
poderá compartilhar alguns dados seus que interessam ao site, como ocorre com dados de consumo.

A "produção" é o terceiro aspecto destacado por [Buckingham 2010], para quem o "letramento envolve também saber quem está comunicando para quem e por quê", seja em termos de segurança de navegação, de identificação de influências comerciais e de que modo a informação inicial pode ter sido modificada a partir da publicação feita em um ou em outro site.

Por fim, o quarto aspecto remete ao sentido de "audiência". Trata-se da consciência que os usuários precisam ter acerca de como "têm acesso aos sites, como são abordados e guiados (ou estimulados a navegar) e como são reunidas informações sobre eles. Significa também reconhecer as diversas formas como a mídia é utilizada [...] por diferentes grupos sociais, e refletir sobre como ela é usada no cotidiano - e como pode ser usada de modo diferente" [Buckingham 2010, p. 51]. Não se pode ignorar a utilização de dados de pesquisa para direcionar novas pesquisas ou, ainda, a identificação de perfil de usuário de rede social para publicidade dirigida, fatos que se mostraram realidade recentemente.

Conforme já destacado e considerando os quatro aspectos apontados, é possível verificar que o letramento digital, de fato, é um processo de construção de senso crítico por parte das pessoas usuárias de tecnologias digitais, uma tomada de consciência de vários elementos relevantes para a ampla compreensão do que se está fazendo no mundo digital. Todavia, a crítica, por si só, não é suficiente para que a pessoa se torne protagonista de sua própria história no uso de ferramentas digitais, sendo necessária uma ação correspondente, qual seja, o uso consciente das tecnologias digitais, conforme se observará a seguir.

\section{Uso Consciente das Tecnologias Digitais}

A Alfabetização Digital e o Letramento Digital, como exposto até aqui são passos fundamentais para a realização do processo de Inclusão Digital. Entretanto, para que se atinja a Inclusão Sociodigital, ou seja, uma Inclusão Digital que vá além da instrumentalização técnica dos usuários de tecnologias, que seja qualitativamente superior, argumenta-se neste trabalho que mais uma etapa deve ser atingida. Tal etapa refere-se ao fomento do Uso Consciente das Tecnologias Digitais.

O uso consciente de uma ou mais tecnologias digitais pode ser entendido como a aplicação qualificada, por um sujeito, dos recursos tecnológicos na realização de uma atividade específica, a qual faz parte de um objetivo final maior. A qualificação aqui em questão diz respeito ao fato de que essa aplicação deve ser previamente planejada e conscientemente alocada no conjunto de passos necessários para o alcance do objetivo final pretendido. Ou seja, para que se atinja o grau de refinamento necessário para a ideação prévia dos passos da atividade e da sua execução consciente, é fundamental que as tecnologias em questão sejam internalizadas pelo sujeito em um patamar qualitativamente superior. Para além da simples instrumentação, as tecnologias devem se tornar "ferramentas mentais" do sujeito.

Como exemplo, pode-se considerar o processo de aprendizagem de uma nova linguagem ou idioma. Nesse processo, primeiro conhecem-se as ferramentas disponíveis 
(palavras, regras gramaticais, construção de frases, etc.). Num segundo momento apropria-se do uso inicial do idioma por meio da aplicação da língua em contextos simplificados. A partir daí, com a prática, o estudo e a mediação contínua, começa-se a entender outros usos e articulações possíveis entre as ferramentas aprendidas no início. Nessa etapa, dá-se início a internalização dos signos da nova língua a fim de que estes façam parte da organização do pensamento. Ou seja, passa-se a ser possível o pensamento por meio dos novos signos apreendidos. A nova língua é, então, utilizada como parte do processo de ideação do sujeito. Uma nova "ferramenta mental" capaz de produzir formas mais elaboradas de pensamento.

A teoria de [Vigotski 2010], bem como os preceitos da Pedagogia HistóricoCrítica [Saviani 2018], permite-nos fundamentar o desenvolvimento do uso consciente de tecnologias definido acima. Como ponto de partida, é interessante situar a questão da consciência e de seu desenvolvimento para Vigotski. O trabalho de [Martins 2013] detalha esse ponto.

Segundo a autora, o desenvolvimento da consciência dos sujeitos, ou o autocontrole da conduta, está dialeticamente relacionado com a formação das Funções Psíquicas Superiores (FPS). Estas, em oposição às funções psíquicas elementares que tem origem no aparato biológico humano, são funções mentais complexas (pensamento abstrato, atenção voluntária, memória lógica,etc.) que possuem origem sócio-cultural e superam a mera manifestação imediata da realidade [Martins 2013]. Através das funções superiores, a representação do real é mediada por meio da apreensão de objetivações histórica e culturalmente formadas.

Ainda em consonância com [Vigotski 2010], a formação das FPS é diretamente dependente do apropriação de uma forma desenvolvida de conhecimento. Aquela formada a partir de Conceitos Científicos. Enquanto a categoria de Conceitos Espontâneos refere-se aos conceitos formados no cotidiano, por meio de necessidades diretas, os conceitos científicos, por sua vez, são de um tipo superior, formados através de atividades mediadas e intencionais. Conceitos espontâneos são conceitos não sistematizados e que possuem pouca capacidade de abstração. Por outro lado, Conceitos Científicos não se relacionam diretamente com o objeto, mas sim, pela mediação de outros conceitos, compondo uma espécie de sistema de conceitos. Isto é, são sistematizados. A partir da apropriação de conceitos científicos, as FPS são desenvolvidas.

É importante notar, entretanto, que conceitos científicos e conceitos espontâneos não são opostos entre si. [Martins 2013] deixa claro que conceitos científicos surgem da superação por incorporação dos conceitos espontâneos. Em outras palavras, conceitos científicos se formam pela tomada de consciência de outros conceitos, potencialmente espontâneos.

Nesse sentido, o presente trabalho apoia-se na ideia de que, para o alcance do uso consciente da tecnologia é necessário que a apropriação do artefato tecnológico pelo sujeito seja baseado na formação de conceito científicos. Estes, por sua vez, irão, dialeticamente, proporcionar o desenvolvimento de sua consciência.

Compreende-se que as atividades realizadas pela Alfabetização Digital e pelo Letramento Digital sejam capazes de proporcionar a formação de conceitos espontâneos. Contudo, para o desenvolvimento do uso consciente da tecnologia, isto é, do desenvolvi- 
mento de conceitos científicos referentes à tecnologia, é necessário um passo adicional. Este passo deve ser alvo direto de projetos ou processos de Inclusão Sociodigital.

Segundo [Sforni 2014], a aprendizagem de conceitos científicos têm especificidades que devem ser consideradas. Uma delas é a necessidade da mediação entre sujeito e objeto (tecnologia) por um agente externo, potencialmente um professor. A autora aponta que "o ensino é o que rompe com esse aparente círculo de autodeterminações [dos conceitos espontâneos]" [Sforni 2014, p. 182, grifo nosso]. Assim, salienta-se para a importância de ações direcionadas e intencionais para a formação do uso consciente da tecnologia. Portanto, projetos ou processos de Inclusão Sociodigital precisam, ao propor suas ações, levar em consideração a promoção do desenvolvimento de conceitos científicos. Ter ações específicas que visem a superação da simples instrumentalização tecnológica.

Por meio do alcance do uso consciente da tecnologia, isto é internalizada pelo sujeito, o artefato tecnológico se torna uma "ferramenta mental". A partir desse ponto a tecnologia pode ser utilizada como meio, e não como fim, para uma atividade. Abre-se, assim, espaço para o empoderamento do sujeito e a superação de suas vulnerabilidades, uma vez que, suas ações podem, agora, ser potencializadas para seus reais objetivos.

\section{Um Novo Olhar e Perspectivas de Pesquisa}

A sistematização desse trabalho teve como objetivo delinear um conceito prévio do que é o uso consciente de tecnologias e de que este elemento é essencial para uma inclusão sociodigital efetiva.

O fechamento deste primeiro ciclo de discussões sobre o uso consciente das tecnologias trouxe para os membros do Grupo de Pesquisa Educação e Tecnologias: Pessoas e Protagonismos, um novo olhar sobre suas práticas e novas perspectivas de pesquisas e ações na sociedade. Com este novo olhar foi possível verificar que as atividades extensionistas do grupo de pesquisa promovem ações que oportunizam uma experiência empírica de uso consciente de tecnologia, principalmente para os acadêmicos extensionistas. Isto é possível porque, para chegar na etapa de execução da atividade na comunidade atendida, os acadêmicos necessitam sistematizar cientificamente o conhecimento que já têm sobre o tema que será tratado no projeto, a fim de compreender como as tecnologias afetam de maneira diferenciada as diversas áreas da sociedade (saúde, educação, cultura, indústria, comércio, etc).

A sistematização científica do conhecimento possibilita aos acadêmicos vislumbrar o enraizamento que um conceito base inicial tem, bem como suas diversas intersecções com diferentes áreas de conhecimento. Essa compreensão permite desenvolver atitudes conscientes que torna possível planejar ações com intencionalidades e buscar resultados previamente esperados. Como exemplos, destacam-se três atividades extensionistas já promovidas pelo grupo, as quais são descritas a seguir.

A primeira atividade foi uma "Oficina de programação de computadores para crianças". Esta oficina foi realizada na Escola Estadual Dom Pedro II, em Curitiba/PR, no ano de 2016 com alunos do 6o. ano do ensino fundamental. O objetivo foi aprimorar o raciocínio lógico das crianças e, com isso, auxiliar na prática de resolução de problemas e motivá-las para as atividades escolares que exigem esse tipo de habilidade 
[Rosa et al. 2019]. Acadêmicos de um Curso Superior de Tecnologia em Análise e Desenvolvimento de Sistemas da UFPR foram formados para ministrar essa oficina dentro do contexto do Projeto de Extensão Construindo Saberes Com o Uso de Computador e Internet.

Uma primeira diferenciação que esses acadêmicos extensionistas tiveram que fazer foi: ensinar a programar computadores exige conhecimentos e habilidades diferentes da atividade de programar computadores. Ou seja, para se ensinar algo para alguém é necessário sistematizar o conhecimento e compreender como o aprendizado ocorre. Para tanto, os acadêmicos tiveram que integrar os seus conhecimentos da área de computação e informática com os conhecimentos da área de educação, a fim de conseguir propor, elaborar e executar atividades que tinham a intenção de proporcionar aprendizado.

Enfim, essa atividade promoveu nos acadêmicos extensionistas uma conscientização e um novo olhar sobre as tecnologias, pois foi possível para eles compreenderem que estas são um meio para atingir um objetivo e que trazem resultados diferentes com base nas metodologias de uso que são aplicadas. Já para as crianças foi possível proporcionar uma conscientização inicial de que o computador pode ajudá-las a desenvolver novas habilidade e aprimorar outras, além de desmistificar o senso comum entre elas: 'quem pensa é a máquina e quem executa é o homem'. Além disso, elas perceberam que o computador e a Internet permite realizar uma gama diversificada de atividades e não somente jogos e redes sociais.

A segunda atividade de extensão tratou dos efeitos jurídicos dos atos praticados pelos adolescentes em meios digitais e o uso consciente das tecnologias digitais. Para tanto, acadêmicos do Curso Superior de Tecnologia em Gestão Pública, da UFPR, e uma das docentes integrantes do Grupo de Pesquisa Educação e Tecnologias: Pessoas e Protagonismos, estruturaram uma atividade que foi aplicada no Colégio Estadual Santa Rosa, em Curitiba/PR, em 2019. Tal atividade teve como objetivo inicial identificar o grau de conhecimento acerca das consequências jurídicas das ações que 63 estudantes do $8^{\circ}$ ano do referido colégio praticam, de forma corriqueira, quando têm acesso a dispositivos tecnológicos e, na sequência, realizar atividades de promoção de uso consciente de tais dispositivos.

Para alcançar tais objetivos, a dinâmica utilizada contemplou as seguintes fases: 1) Identificação dos dez assuntos mais relevantes relacionados ao uso de tecnologias digitais, o que foi feito por meio de um formulário eletrônico, e que apontou os seguintes temas: a) injúria, calúnia, difamação e preconceito; b) exposição de imagem própria e alheia; c) assédio; d) bullying e ciberbullying; e) fake news; f) falsa identidade; g) injúria racial e racismo; h) pirataria; i) golpe financeiro e j) obtenção e roubo de dados. 2) Com os temas identificados, os acadêmicos e a docente pesquisaram ferramentas que pudessem atender ao objetivo inicial de promover o uso consciente das tecnologias, tendo em mente a compreensão dos resultados jurídicos que os atos descritos produzem, o que foi feito com a verificação do conhecimento prévio sobre os temas que os estudantes tinham, utilizando, para tanto, um questionário, elaborado com base na Escala Likert e com a organização de uma dinâmica de sensibilização sobre o tema, o que foi feito com uma visita no Colégio, nos horários de aula das disciplinas de Língua Portuguesa e de Artes, parceiras da atividade. 3) Na sequência, os acadêmicos e a docente pesquisadora retornaram ao Colégio para realizar a discussão dos temas trabalhados e para o início de trabalhos 
de realização de uma cartilha de "Boas práticas para o uso da Internet", proposta como resultado de um concurso entre grupos de estudantes que participaram das discussões anteriores. 4) Por fim, os acadêmicos e a docente pesquisadora retornaram ao Colégio para avaliação das cartilhas, junto com a Direção e docentes do Colégio, o que foi feito com a constituição de uma banca de avaliação e premiação das melhores cartilhas. Em tal momento, novamente foi aplicado um questionário para verificação de apreensão dos conteúdos trabalhados.

Como resultado final, observou-se que houve uma modificação positiva na compreensão dos efeitos dos atos individuais praticados em meio digital, o que aponta para o uso mais consciente das tecnologias digitais. Ao mesmo tempo, verificou-se que as atividades aplicadas atenderam parcialmente ao objetivo inicial, o que mostra a necessidade de, a partir dos resultados empíricos, adequar as ferramentas utilizadas se o público continuar sendo o $8^{\circ}$ ano do ensino fundamental, ou utilizar as mesmas ferramentas mas com estudantes do Ensino Médio.

A terceira atividade, um curso de extensão, realizado no ano de 2018, teve como objetivo fortalecer a convivência entre as gerações, possibilitando uma troca de experiências entre crianças ( $6^{\circ}$ ano do ensino fundamental) e seus avós, contribuindo para a inclusão digital da pessoa idosa por meio do smartphone e suas tecnologias, bem como, do exercício da cidadania por parte dos alunos do Colégio Estadual Santa Rosa [Ferreira et al. 2019]. O curso contou com a participação de dois docentes integrantes do Grupo de Pesquisa Educação e Tecnologias: Pessoas e Protagonismos, das áreas da saúde e da computação, e acadêmicos do Curso Técnico em Agente Comunitário de Saúde e do Curso Superior de Tecnologia em Análise e Desenvolvimento de Sistemas.

Durante o curso, foram abordados com os alunos, por meio de rodas de conversa e aulas dialogadas, temas como "Aspectos bio psico sociais que envolvem o processo de envelhecimento" e "o uso de smartphones e as possibilidades tecnológicas desse tipo de aparelho às pessoas idosas". Ao final do curso, os alunos tiveram como tarefa dialogar com seus avós para identificar possíveis demandas na rotina de seus familiares em que o uso smartphone poderia os auxiliar. Uma vez identificadas, coube aos próprios alunos ensinar seus avós como utilizar propriamente o smartphone.

Nesse curso procurou-se indicar aos alunos como ocorre o processo de envelhecimento e, nesse contexto, como diferentes possibilidades de uso do smatphone poderiam auxiliar pessoas idosas. Ou seja, não se tratou de um curso para o ensino do uso do smatphone, uma vez que os alunos já dominavam (de maneira imediata) a maioria das funcionalidades abordadas. Mas sim, de dar um direcionamento a esse uso, de complexificalo, de torná-lo parte integrante de um processo maior: auxiliar na rotina de idosos e, indiretamente, melhorar a convivência entre gerações. Assim, através da mediação de conceitos espontâneos previamente existente nos alunos, notou-se a possibilidade de um desenvolvimento qualitativo no uso de tecnologias. Um uso direcionado, não tendo a tecnologia como fim, mas como meio.

As experiências acima relatadas apontam indícios de que o trabalho extensionista, atrelado à pesquisa, pode promover o uso consciente da tecnologia, sendo este, essencial para uma inclusão social efetiva. Porém, ainda são muitos os desafios teóricos e metodológicos que envolvem a criação e a execução de atividades de extensão que alcancem 
a promoção do uso consciente da tecnologia. O presente trabalho não busca esgotar tal discussão, mas sim, propor o seu início e alguns direcionamentos.

Nesse contexto, dentre possíveis perspectivas de pesquisas sobre o tema, apontamse algumas considerações como ponto de partida:

- Como sistematizar processos de aprendizagem que promovam o uso consciente de tecnologias?

- Qual o impacto da subjetividade na experiência consciente?

- É possível criar procedimentos padrão e generalizados para tornar efetivo o uso consciente de tecnologias? Ou, para cada situação e cada público é necessário construir ferramentas e procedimentos específicos, respeitando características específicas?

Assim sendo, a pesquisa e a extensão tornam-se indissociáveis pois o conhecimento produzido sobre qualquer tema pode e deve ser desenvolvido a partir de uma situação real e pode ser reproduzido em outras situações semelhantes, desde que adequações sejam feitas de modo a respeitar o público que irá participar da atividade. Foi possível, a partir das atividades desenvolvidas, verificar que o uso consciente de tecnologias é um requisito para tornar efetiva a inclusão sócio-digital.

Portanto, o Grupo de Pesquisa Educação e Tecnologias: Pessoas e Protagonismos, compreendeu que é necessário que o tema seja aprofundado, não somente no âmbito das pesquisas individuais mas sim coletivamente, de modo que o caminho para se chegar a um uso consciente de tecnologias possa ser traçado e compartilhado com as pessoas que se interessarem pelo assunto.

\section{Considerações Finais}

Partindo das provocações iniciais feitas pelas questões destacadas no início do texto, e sem pretensão de esgotar o assunto, o presente trabalho procurou apontar elementos necessários a um percurso formativo que parte da alfabetização digital, passa pelo letramento digital e, ao chegar à inclusão digital, transcende-a para chegar a uma proposta de novo destino, a inclusão sociodigital com o uso consciente de tecnologias digitais, com amplo alcance nas comunidades que receberam as atividades descritas.

As atividades de pesquisa e de extensão já realizadas pelo Grupo de Pesquisa Educação e Tecnologias: Pessoas e Protagonismos, tornaram possível constatar que nem sempre uma pessoa que domina a técnica por detrás da tecnologia digital consegue perceber o alcance de seus atos quando desenvolve tal tecnologia ou quando acessa conteúdos disponíveis na web. A construção de um senso crítico, neste sentido, pode se mostrar insuficiente se ele vier desacompanhado de uma ação efetiva por parte de quem o tem. Neste sentido, não basta ser crítico, é necessário dar um passo adiante e usar o conhecimento adquirido e a crítica elaborada para fazer um uso consciente do que está disponível em termos de tecnologias digitais.

E é exatamente com essa preocupação, expressada no início destas reflexões pelas questões postas, que esta discussão é encerrada, o que dá combustível na busca de caminhos para identificar tanto o que pode ser considerado uso consciente da tecnologia quanto de que forma é possível mensurar a efetividade das atividades do grupo em ações e pesquisas cujo objeto central seja uma inclusão sociodigital efetiva, dando condições às pessoas para se tornarem protagonistas de suas ações no mundo digital. 


\section{Referências}

Buckingham, D. (2010). Cultura digital, educação midiática e o lugar da escolarização. Educação \& Realidade, 35(3):37-58.

Castells, M. (2002). A era da informação: Economia. Sociedade e Cultura, 1:87-99.

Castro, L. M. C. (2004). A universidade, a extensão universitária e a produção de conhecimentos emancipadores. (Ainda existem utopias realistas). $\mathrm{PhD}$ thesis, Universidade Federal do Rio de Janeiro.

Colello, S. M. G. (2016). Alfabetização ou alfabetização digital. International Studies on Law and Education, 23.

de Jesus, A., Kutzke, A. R., Ferreira, I. d. R. C., and Carbonera, S. M. (2020). Tecnologias e conhecimentos-pessoas e protagonismos: Uma proposta de projeto de extensão. Revista Conexão UEPG, 16:1-12.

de Lima, F. R. B. and Zavam, A. (2016). Letramento digital ou alfabetização digital? estabelecendo as diferenças e atualizando a questão em tempos de nativos digitais. In V Colóquio Nacional de Hiperterxto - CHIP, volume 2, page 125.

Ferreira, I., Kutzke, A. R., Feger, J. E., Jesus, A., and Carbonera, S. (2019). Reforçando os laços de convivência entre gerações por meio do uso do smartphone e suas tecnologias. In Anais dos Workshops do Congresso Brasileiro de Informática na Educação, volume 8, page 1393.

Gabriel, R. (2017). Letramento, alfabetização e literacia: Um olhar a partir da ciência da leitura. Revista Prâksis, 2:76-88.

Jesus, A. (2012). Informática cidadã. In Informática para o Desenvolvimento Humano, volume 1, pages 59-89. Secretaria de Estado da Justiça, Cidadania e Direitos Humanos, Curitiba, 1 edition.

Martins, L. M. (2013). O Desenvolvimento do Psiquismo e a Educação Escolar. Autores Associados, Campinas, 1 edition.

Rezende, M. V. d. (2016). O conceito de letramento digital e suas implicações pedagógicas. Texto Livre: Linguagem e Tecnologia, 9(1):94-107.

Rosa, A., Nakoneczny, C., Lubke, C., Igarashi, G., Pereira, V., Jesus, A., Kutzke, A. R., et al. (2019). Extensão universitária: uma experiência com ensino de programação para crianças. In Anais do Workshop de Informática na Escola, volume 25, page 1199.

Saviani, D. (2018). Escola e Democracia. Autores Associados, Campinas, 43 edition.

Sforni, M. S. d. F. (2014). Aprendizagem conceitual e organização do ensino: contribuições da teoria da atividade. JM Editora, Araraquara, 1 edition.

Tarouco, L. and Ávila, B. (2007). Multimídia na alfabetização digital com fluência para a autoria. RENOTE-Revista Novas Tecnologias na Educação, 5(2).

Vigotski, L. S. (2010). A construção do pensamento e da linguagem. Martins Fontes, São Paulo, 2 edition. Tradução de Paulo Bezerra. 